\title{
Design and Effects of Symmetrical Slotted Array on Microstrip Ultra wide Band Antenna

\author{
Mohsin M. Mulani ${ }^{\# 1,}$ Vidya V. Deshmukh ${ }^{\# 2}$ \\ ${ }^{\#}$ Electronics and Telecommunication Engineering, Pune UniversityAISSMS College of Engineering Pune \\ Maharashtra, India. \\ ${ }^{\#}$ Electronics and Telecommunication Engineering, Pune UniversityAISSMS College of Engineering Pune \\ Maharashtra, India.
}

\begin{abstract}
The given paper presents an Ultra Wide Band (UWB) which is simplified and compacted on a rectangular micro strip patch. The micro strip patch of rectangular shape has been narrowed at the bottom and the ground plane in cut-shorted at the top center. The substrate is FR4 substrate with the dimension of (28x29x1.6) $\mathrm{mm}$ and permittivity of 4.4. The antenna has been designed on HFSS v11.0 software simulation tool. The simulated results are shown in this paper. The designed antenna exhibits an impedance bandwidth between 3.3-16.9 GHz (for $\left.S_{11}<-10 \mathrm{~dB}\right)$. The designed antenna has stable VSWR (1.0-2.0) and stable E and $H$ plane over the given bandwidth range. The designed UWB antenna resonates at 6 different frequencies (at $3.9 \mathrm{GHz}, 6.5 \mathrm{GHz}, 3.9 \mathrm{GHz}, 8.5 \mathrm{GHz}, 11.2 \mathrm{GHz}, 14.3 \mathrm{GHz}$ and $15.3 \mathrm{GHz}$ ). The Ultra wide bandwidth has been achieved by implementing the concept of frequency independence method. The antenna exhibits better UWB characteristics suitable for UWB applications.
\end{abstract}

Keywords:Bandwidth,FCC, Group delay, Omni-directional, UWB, VSWR.

\section{INTRODUCTION}

After the approval of frequency band between the ranges 3.1 to $10.6 \mathrm{GHz}$ by Federal Communications Commission (FCC), most of academic and industrial organizations have started their research on designing more compact and efficient antennas to perform in this frequency range [1]. It is predicted that this UWB technology will provide ultra high speed data transmission with very low power consumption. It can also be anticipated that these UWB antennas are recommendable for various applications like medical imaging, indoor and radar positioning, see through objects. Printed microstrip antennas are light weight, low cost, small sized, easily available materials that draw them towards designing of UWB antenna development [3].

Normally any Microstrip patch has a drawback of narrow impedance bandwidth. Numbers of research have been done on enhancing the impedance bandwidth. Many of them include introducing a slot within the plane of microstrip antenna. Slot may be of any shape weather a square-ring shaped or U-shaped slot [5]. The operational bandwidth can also be increased by methods like stacked patch which is electromagnetically coupled, integrated band pass filter enhanced patch antenna, meander lined ground plane and feeding techniques where the gap is coupled[6].

In the present paper, a simply small and compact printed microstrip fed patch antenna is put forward. The antenna exhibits a wide impedance bandwidth between 3.3-16.9 GHz. The antenna exhibits 6 different resonating frequencies. The VSWR characteristics for desired range are acceptable and thus it satisfies the UWB system requirement. The outline of this paper is as follows. Section consists of antenna configuration. Section 3 consists of design and analysis of proposed antenna. And finally section 4 is the conclusion of this paper.

\section{ANTENNA CONFIGURATION}

The proposed designed antenna is located in $\mathrm{x}-\mathrm{y}$ plane $\mathrm{z}$ - axis is normal to the plane of antenna. The proposed antenna is shown in figure 1, out of which left one corresponds to the radiating patch whereas right one resembles the side view plane [7]. While designing the antenna the concept of frequency independence have been under taken. This concept depicts that if a particular antenna is designed using the frequency independence concept, then the performance characteristics of that particular antenna is independent to the changes in the frequency. Out of the types of frequency independent methods, the proposed antenna is designed using the combining principle, which states that the performance characteristics increases with corresponding changes in the design[7].

All the units for the dimensions of proposed antenna are in millimeter $(\mathrm{mm})$.The distance between rectangular slots is $1 \mathrm{~mm}$, which lies within the rectangular patch. Figure b shows the step by step iterations of achieving the ultimate design. The iterations individually exhibit their performance characteristics and enhanced bandwidth. But the ultimate design shown in figure provides better results than any other iteration. The antenna is compacted within the dimensions of substrate $(28 \times 29 \times 1.6) \mathrm{mm}$. The thickness of substrate is $1.6 \mathrm{~mm}$ and that of radiating patch and ground plane is $0.2 \times 10^{-3} \mathrm{~m}$. 


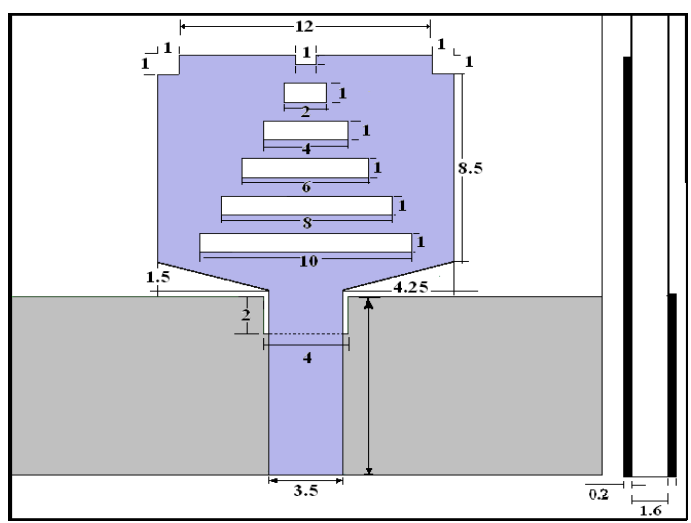

Fig. 1: Geometry of proposed Microstrip antenna.

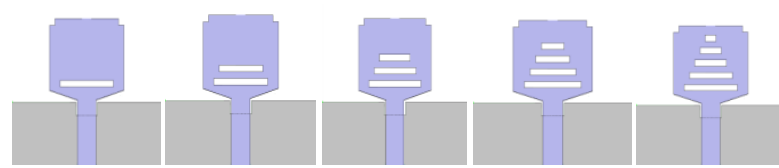

Fig. 2: Step by Step Iteration for Ultimate design.

\section{ANTENNA DESIGN AND ANALYSIS}

The antenna is designed in one of the best simulation software named as HFSS v1.0 (High Frequency Structure Simulator). In this software we are able to find out almost all parameters of any antenna.

\section{A. Design formulae}

$$
\begin{aligned}
\mathrm{W} & =\frac{1}{2 f_{r} \sqrt{\mu_{0} \epsilon_{0}}} \sqrt{\frac{2}{\epsilon_{\text {reff }}+1}} \\
\epsilon_{\text {reff }} & =\frac{\epsilon_{r}+1}{2}+\frac{\epsilon_{r}-1}{2}\left[1+12 \frac{h}{W}\right]^{-1 / 2} \\
\frac{\Delta L}{h} & =0.412 \frac{\left(\epsilon_{r}+0.3\right)\left(\frac{W}{h}+0.264\right)}{\left(\epsilon_{r}-0.258\right)\left(\frac{W}{h}+0.8\right)} \\
L & =\frac{1}{2 f_{r} \sqrt{\epsilon_{\text {reff }}} \sqrt{\mu_{0} \epsilon_{0}}}-2 \Delta L
\end{aligned}
$$

\section{B. Design steps}

1. Following is design of a rectangular patch antenna of length ' $L$ ' and width ' $W$ ' for FR4 substrate $(\varepsilon=$ 4.4) of thickness ' $\mathrm{h}$ ' $=1.6 \mathrm{~mm}$ and frequency $f_{r}=6.5 \mathrm{GHz}$.

2. The width $\mathrm{W}$ of proposed antenna is found using equation (1).

3. Use the calculated $\mathrm{W}$ to find effective permittivity $\epsilon_{\text {reff }}$

4. Now find out the value of $\Delta \mathrm{L}$ using equation (3).

5. Finally find out the actual length $L$ from equation (4)[10].

In this manner the basic antenna design for solution frequency of $6.5 \mathrm{GHz}$ is achieved [10]. The intrinsic properties of FR4 substrate cause the curve to differ slightly from each other. According to [2], a wider bandwidth can be obtained by introducing a slot on the active region of patch antenna and introducing a taper at the bottom edge of the radiator. The resonating frequency is related to the width of the patch or the width of slot [8].

The relation between width $\mathrm{W}$ and the resonating frequency is given in following table 1 . The relations are easily found by substituting values of $W_{\text {slot }}$ in equation (1). 


\begin{tabular}{|c|c|c|}
\multicolumn{3}{|c|}{ TABLE I } \\
\hline $\mathbf{W}_{\text {slot }}$ & Theoretical $\boldsymbol{f}_{\boldsymbol{r}}$ & Practical $\boldsymbol{f}_{\boldsymbol{r}}$ \\
\hline $14 \mathrm{~mm}$ & $6.59 \mathrm{GHz}$ & $6.5 \mathrm{GHz}$ \\
\hline $10 \mathrm{~mm}$ & $9.1 \mathrm{GHz}$ & $8.5 \mathrm{GHz}$ \\
\hline $8 \mathrm{~mm}$ & $11.40 \mathrm{GHz}$ & $11.2 \mathrm{GHz}$ \\
\hline $6 \mathrm{~mm}$ & $15.20 \mathrm{GHz}$ & $15.3 \mathrm{GHz}$ \\
\hline
\end{tabular}

The designed structure for antenna is shown in figure 3. The analysis of UWB antenna is discussed in following

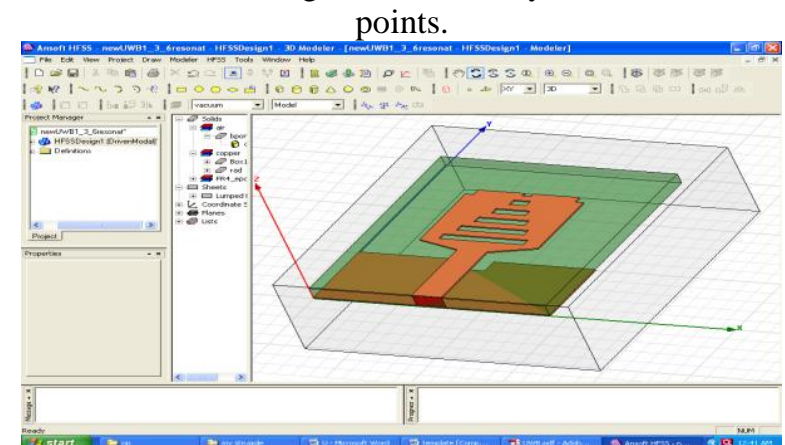

\section{Return Loss}

Fig.1 Prototype of proposed antenna designed in HFSS v11.0

The antenna displays an acceptable impedance bandwidth between 3.3 to $16.9 \mathrm{GHz}$. The return loss of antenna lowers beyond-38dB. The overall impedance bandwidth lies below $-10 \mathrm{~dB}$ (i.e. $\mathrm{S}_{11}<-10 \mathrm{~dB}$ ). The return loss curve also depicts the 5 more resonating frequencies other than the solution frequency $(6.5 \mathrm{GHz})$. The values for frequencies at different frequencies are highlighted by marker. Apart from $6.5 \mathrm{GHz}$, other resonating frequencies are $3.9 \mathrm{GHz}, 8.5 \mathrm{GHz}, 11.2 \mathrm{GHz}, 14.3 \mathrm{GHz}$ and $15.3 \mathrm{GHz}$ as shown in figure 4.Thus we can say antenna satisfies the impedance bandwidth for UWB applications.. Initially for the first Iteration as shown in figure the antenna exhibits resonant frequency at $6.6 \mathrm{GHz}$. But as there is increase in the rectangular slots, antenna possesses few more resonant frequencies; this is due to the combining principle of frequency independent methods for acquiring wide bandwidth [6].

Bandwidth enhancement can be acquired by tapering the patch diagonally at the bottom edge. Because of this technique there is a discontinuity in the microstrip line [2]. This results in the second resonating frequency at $8.5 \mathrm{GHz}[6]$.

\section{Radiation Pattern}

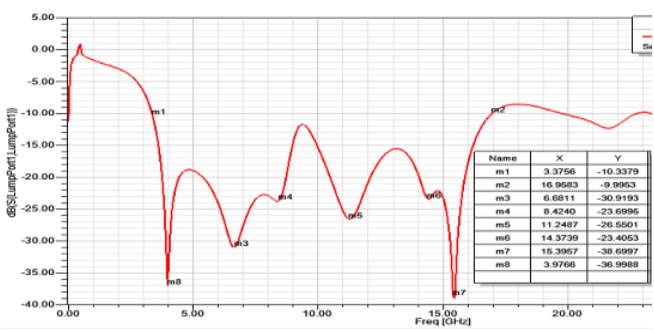

Fig. 4 Return loss

Antenna exhibits an Omni directional radiation pattern. Figure shows VSWR plot of the antenna. From the given figure it is clear that the VSWR values for antenna remain between 1.5 and 2.0. Additionally a smith chart plot gives evidence for stable VSWR values over operating impedance bandwidth [6]. Figure 5 shows 3 -Dimensional radiation pattern. Figure 6 shows the VSWR plot


Fig. 5: Radiation Pattern. 


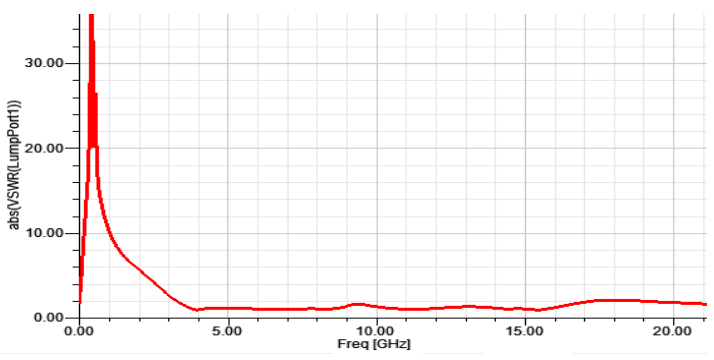

Fig. 6: VSWR plot.

\section{E. Group Delay}

Group delay is one of the most vital criterions to find out the performance of UWB technology. The Group delay is nothing but the shortest pulse width that transmitted by that particular antenna with minimal distortion. The group delay is below $0.1 \mathrm{~ns}$ for the given antenna. The group delay is plotted in figure 7 .

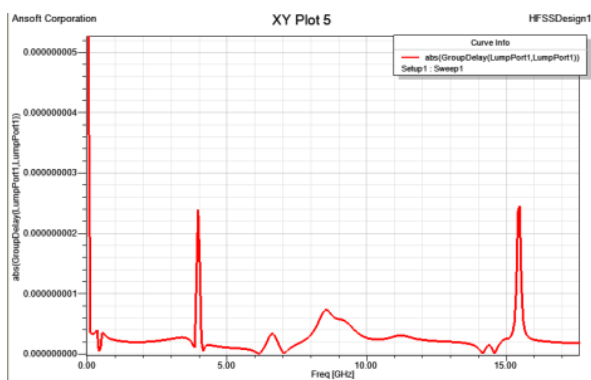

Fig.7: Group delay

\section{CONCLUSION}

A micro strip patch UWB antenna is proposed, which satisfies the UWB bandwidth requirement (between 3.3-16.9 GHz). The antenna possesses acceptable VSWR and return loss characteristics. The 3D radiation pattern is Omni-directional. Antenna exhibits acceptable value of group delay with gain of about $2.5 \mathrm{dBi}$. Thus the proposed antenna fits to the application of UWB technology.

\section{Future Scope:}

UWB communications can be used in jamming applications. Antennas with resonant frequencies below 6 $\mathrm{GHz}$ can be used for file transfer in cell phones; one can play high definition games locally with friends. Resonant frequencies higher than $8 \mathrm{GHz}$ can be used in automatic target reorganization and tracking.UWB antenna can be used in radio frequency sensitive environment like hospitals. One can do energy harvesting with the help of low profile UWB antenna. This can be done by using the solar energy as the core source of energy for UWB systems.

\section{REFERENCES}

[1] BaskaranKasi, Lee Chia Ping, Chandan Kumar Chakrabarty, "A Compact Microstrip antenna for Ultra wide band Application," European Journal of Scientific Research, ISSN 1450-216X Vol.67 No.1 (2011), pp. 45-51

[2] K.C. Gupta, R. Garg, I. Bahl and P. Bhartia, "Microstrip Lines and Slotlines," Artech House, 2nd Ed, 1996.

[3] Y. Zehforoosh, C. Ghobadi and J. Nourinia, "Antenna design for Ultra Wideband Application Using a New Multilayer Structure," Progress in Electromagnetics Research Symposium, Beijing, 26-30 March 2007.

[4] S. Sadat, M. Fardis, F. Geran, and G. Dadashzadeh, "A compact microstrip square-ring slot antenna for UWB applications,"Progress In Electromagnetics Research, Vol. 67, 173-179, 2007.

[5] K. F. Lee, K. M. Luk, K. F. Tong, S. M. Shum, T. Huyn and R. Q. Lee, "Experimental and Simulation Studies of the Coaxially Fed U-slot Rectangular Patch" IEEE Proceedings of Microwave Antenna Propagation, Vol. 144, No. 5, October 1997, pp. 354-358.

[6] FCC report and order for part 15 acceptance of ultra wideband UWB) systems from 3.1-10.6 GHz, Washington, DC, 2002.

[7] Werner Wiesbeck,GrzegorzAdamiuk, Christian Sturm, "Basic Properties and Design Principles of UWB antennas," Microwave and Optical Technology Letters, Vol. 29, No.2, April 20 2001, pp. 95-97.

[8] Ramesh Garg,PrakashBhartia,InderBhal,ApisakIttipiboon "Microstrip Antenna Design handbook," ISBN-0890065136, pp. 253-268.

[9] Hans Gregory Schantz, “ A BRIEF HISTORY OF UWB ANTENNAS ”,Next-RF, Inc. 4811Cove Creek Drive Brownsboro, AL 35741

[10] C.A.Balanis, "Antenna Theory,” Jhon Wiley and Sons, pp. 811-835. 